\title{
Effectiveness and Impact on Adherence of a New Fixed-Dose Combination of Ivabradine and Metoprolol in a Wide Range of Stable Angina Patients in Real-Life Practice
}

\author{
Dimitar Divchev - Georg Stöckl on behalf of the study investigators
}

Received: June 28, 2019 / Published online: August 13, 2019

(C) The Author(s) 2019

\section{ABSTRACT}

Introduction: The antianginal effectiveness of ivabradine administration in addition to betablockers has been shown in patients with stable angina. The first fixed-dose combination (FDC) of ivabradine and metoprolol is now available and its evaluation in various stable angina patient populations relevant to clinical practice would be useful.

Methods: In this 4-month, prospective, multicenter, observational study, the effectiveness and tolerability of the metoprolol/ivabradine FDC was assessed in patient subgroups specified according to age, coronary artery disease (CAD) duration, Canadian Cardiovascular Society (CCS) class, comorbidities, and previous myocardial infarction (MI) or revascularization. Heart rate (HR), angina attack frequency, short-acting nitrate (SAN) consumption, functional status, and medication

Enhanced Digital Features To view enhanced digital features for this article go to https://doi.org/10.6084/ m9.figshare.9006647.

D. Divchev ( $\square)$

Department of Cardiology and Angiology,

University Hospital Marburg, Baldingerstrasse, 35043 Marburg, Germany

e-mail: dimitar.divchev@med.uni-marburg.de

G. Stöckl

Department of Medical Affairs, Servier Deutschland GmbH, Elsenheimerstrasse 53, 80687 Munich, Germany adherence were documented at baseline and after 4 months of follow-up.

Results: A total of 747 stable angina patients were included and divided into subgroups. At 4 months, a significant decrease in HR, angina attack frequency, and SAN consumption per week was consistently observed across all patient subgroups. The proportion of CCS class I patients increased significantly from baseline to month 4 . In all patient subgroups, at 4 months, a significant increase was observed in the proportion of patients with self-reported complete adherence. Complete adherence at the final visit was found to decrease with an increasing number of medications. Physicians evaluated the effectiveness and tolerability of the FDC as 'very good' and 'good' for more than $96 \%$ of patients in all analyzed patient subgroups.

Conclusions: Treatment with metoprolol/ivabradine FDC significantly improved angina symptoms and adherence, with an excellent tolerability profile, in stable angina patient subgroups relevant to real-life clinical practice, regardless of age, CAD duration, CCS class, comorbidities, previous MI, or history of revascularization.

Trial registration: ISRCTN51906157.

Funding: This study was sponsored by Servier Deutschland $\mathrm{GmbH}$. Editorial assistance and the Rapid Service Fee were funded by Servier, France.

Plain Language Summary: Plain language summary available for this article. 
Keywords: Adherence; Antianginal combination therapy; Beta-blocker; Clinical practice; Heart rate reduction; Ivabradine; Observational study; Stable angina

\section{PLAIN LANGUAGE SUMMARY}

Angina is a condition that affects more than 100 million patients worldwide. The drug ivabradine administered together with a beta-blocker has been shown to improve angina symptoms. A new formulation exists, in which ivabradine is combined in a single pill with the betablocker metoprolol. This study analyzed the effect of treatment with this new formulation in different groups of patients according to age, duration of disease, functional status, and presence of other health conditions. In all the patient groups analyzed, this treatment decreased the number of angina attacks and the use of nitroglycerine. It also improved functional status. Moreover, the number of patients taking their medicine as prescribed, as reported by patients themselves, increased. This new formulation could therefore provide an opportunity to improve angina symptoms and increase the number of patients following their treatment.

\section{INTRODUCTION}

Ischemic heart disease remains the leading cause of health loss in both sexes [1]. Angina pectoris (AP) due to coronary artery disease (CAD) affects approximately 112 million people in the world [2].

Heart rate (HR) is one of the main determinants of myocardial oxygen consumption. Elevated HR shortens the length of each cardiac cycle and reduces diastolic perfusion time, decreasing oxygen supply. This imbalance leads to myocardial ischemia, which can trigger angina symptoms [3]. In patients with stable angina, most episodes of exercise-induced myocardial ischemia are preceded by an increase in HR [4]. Development of ischemia is related to baseline HR as well as to the extent and duration of HR increase [5]. The frequency of ambulatory ischemic episodes in treated CAD patients is related to their mean HR, with patients with a HR of 80 beats per minute (bpm) experiencing ischemia almost twice as often as those with a HR of $70 \mathrm{bpm} \mathrm{[6].} \mathrm{There} \mathrm{is} \mathrm{also}$ strong evidence supporting the association between HR and mortality in patients with stable angina $[7,8]$.

Reducing resting HR is very important when treating patients with stable angina and CAD, and the latest guidelines for the treatment of stable angina recommend reaching target levels of $\leq 60 \mathrm{bpm}$ [9]. Beta-blockers (BB) are currently recommended as the first-line anti-anginal treatment for reducing $\mathrm{HR}$ and angina symptoms [9]. In the CLARIFY registry, the majority of patients (79\%) with angina symptoms were treated with a BB; however, their average HR was above the target levels. Moreover, among the 7301 patients with angina symptoms, only $25 \%(n=1818)$ had their HR controlled ( $\leq 60 \mathrm{bpm})$ [10].

Combining a $\mathrm{BB}$ with ivabradine has been shown to further reduce the HR of patients with stable angina, along with myocardial ischemia and symptoms of angina [11, 12]. Ivabradine selectively inhibits the funny current $\left(I_{\mathrm{f}}\right)$, which reduces $\mathrm{HR}$, leading to a decrease in myocardial oxygen demand while increasing both coronary filling time and blood flow, thus protecting against ischemia and angina symptoms [13, 14].

In addition to treatment choice and dose, non-adherence of patients to their treatment can explain suboptimal angina control. Approximately $50 \%$ of patients with cardiovascular disease and/or its major risk factors have poor adherence to their prescribed medications [15]. Non-adherence is well-described for asymptomatic conditions such as hypertension, but it has also been observed in symptomatic conditions, including in patients with angina [16]. A study based on patient self-reports found that as many as $54 \%$ of CAD patients were nonadherent to treatment with BBs [17]. Non-adherence to medication is a complex phenomenon affected by several factors [18]. Existing experience points to the number of daily doses as an important predictor of adherence [19]. Simplification of the treatment regimen, for example through the use of fixed-dose 
combinations (FDC), could lead to improved adherence and potential clinical benefit.

The effectiveness and safety of the first FDC formulation of metoprolol and ivabradine was assessed previously in stable AP patients in routine clinical practice [20]. Herein we report an additional analysis of the data obtained in this 4-month prospective observational study, in which the effectiveness of the metoprolol/ ivabradine FDC was assessed in subgroups of patients with different clinical characteristics.

\section{METHODS}

IMPLICOR-NOW was a prospective, observational, multicenter study conducted in Germany from October 2015 to October 2016, under daily practice conditions in 260 centers [20]. Stable AP patients fulfilling criteria for treatment with the new metoprolol/ivabradine FDC (Implicor ${ }^{\mathrm{TM}} 5 / 25,5 / 50,7.5 / 25,7.5 / 50$ ) according to the approved EU indication were eligible for inclusion. Three visits were planned: a baseline examination (visit 1), a control visit after 4 weeks (visit 2), and a final examination after 4 months (visit 3).

Demographic data and general/diseasespecific medical history, information about concomitant diseases, other relevant medical therapies, and reasons for initiation of FDC treatment were recorded at the baseline visit. According to the approved label, the starting dose of the FDC should be equivalent to the dosing of the individual components (ivabradine and metoprolol) before the switch. If necessary to achieve symptom control, the dose could be adjusted during the study to a maximal dose of $7.5 \mathrm{mg}$ ivabradine and $50 \mathrm{mg}$ metoprolol twice daily. Dose reduction is possible in case of a pronounced HR reduction $<50 \mathrm{bpm}$ or occurrence of bradycardic symptoms during treatment.

Patient status was clinically documented at each visit by recording HR, number of weekly angina attacks, use of short-acting nitrates
(SAN), and Canadian Cardiovascular Society (CCS) class. A four-item adherence questionnaire was used to assess medication adherence at baseline compared to study end after 4 months of treatment [20]. "Complete adherence" was defined as the absence of any adherence-related problems reported in the questionnaire. At visit 3, physicians evaluated effectiveness and tolerability of metoprolol/ ivabradine for each patient using a scale with the following categories: 'very good', 'good', 'moderate', and 'poor'.

In the present analysis, these parameters were assessed in patient subgroups specified according to age ( $<60$ years, 60 to $<75$ years, $\geq 75$ years), CAD duration $(<2$ years, 2 to $<5$ years, 5 to $<10$ years, $\geq 10$ years), CCS class (CCS class I, class II, class III and IV), history of renal dysfunction, previous percutaneous coronary intervention (PCI), previous myocardial infarction (MI), diabetes, asthma/chronic obstructive pulmonary disease (COPD), or hypertension.

\section{Compliance with Ethics Guidelines}

All procedures followed were in accordance with the ethical standards of the responsible committee on human experimentation (institutional and national) and with the Helsinki Declaration of 1964, as revised in 2013. Informed consent was obtained from all patients for being included in the study. Ethical approval was granted by the independent ethics commission in Freiburg/Germany (FEKI).

\section{Statistical Analysis}

Due to the observational design of the study, statistical analysis of the results was performed by a descriptive approach. Data are presented as mean values \pm standard deviations (SD) for continuous variables and numbers of patients and/or percentages for categorical variables. Analysis of effectiveness data was performed with data imputation according to the last value 
carried forward method (LVCF). Wilcoxon's signed-rank test and Fisher's exact test were applied as appropriate for assessment of changes between baseline and follow-up visits. Corresponding $p$ values should be interpreted in a descriptive-exploratory way. The $p$ values reported are two-tailed and an alpha level of 0.05 was used to assess statistical significance. No correction of alpha level for multiple testing was performed. All study data were evaluated by an independent statistical institute (ANFOMED $\mathrm{GmbH}$, Mohrendorf, Germany). All statistical analyses have been performed by means of the SAS software system (version 9.4 for Microsoft Windows 10; SAS Institute Inc., Cary, NC, USA).

\section{RESULTS}

Data from the IMPLICOR-NOW study [20] conducted in 747 patients with stable AP were used. Baseline characteristics as well as effectiveness and tolerability in the overall population were reported previously [20]. Following the switch to the metoprolol/ivabradine FDC, effectiveness was assessed in patient subgroups specified according to age, CAD duration, CCS class, history of renal dysfunction, previous PCI, previous MI, diabetes, asthma/COPD, or hypertension.

In all patient subgroups, at 4 months of treatment, a significant decrease was observed in both the mean number of angina attacks and SAN consumption per week (Fig. 1). A significant decrease in HR was also consistently observed across all patient subgroups (Table 1). CCS class was also significantly improved in all patient subgroups, with the proportion of CCS class I patients ranging from $11 \%$ to $35 \%$ at baseline and from $39 \%$ to $71 \%$ at month 4 (Fig. 2).

The proportion of patients with complete adherence in relation to the number of drugs used was assessed at the final visit at 4 months ( $n=715$ patients) and was found to decrease with an increasing number of medications taken by patients (Fig. 3 ; $p=0.0004$ for association). In all patient subgroups, at 4 months of treatment, a significant increase in the proportion of patients with self-reported complete adherence was observed (Fig. 4).

At the last visit, the effectiveness and tolerability of the therapy was evaluated by the physicians as 'very good' or 'good' for more than $96 \%$ of patients in all analyzed subgroups (Table 2).

Adverse events (AEs) were reported in $6.70 \%$ of the patients $<60$ years old and in $5.19 \%$ of the patients 60 to 75 years old. In patients over 75 years, the proportion of patients affected by AEs was $4.35 \%$. The proportion of patients with AEs was higher in patients with renal dysfunction $(7.58 \%)$ than in patients with normal renal function (5.14\%). AEs were reported in $7.75 \%$ of patients with asthma or COPD and in $4.79 \%$ of patients without asthma/COPD. Proportions of patients with AEs were similar between patients with $(5.75 \%)$ and without diabetes (5.14\%), between patients with $(5.27 \%)$ and without hypertension $(5.88 \%)$, and between patients with $(5.58 \%)$ and without a MI $(5.18 \%)$. In patients with CAD known for less than 2 years, AEs were reported in $6.41 \%$. In patients with CAD duration 2 to $<5$ years, $7.49 \%$ were affected by AEs. The lowest proportion of patients with AEs was $2.70 \%$, in the patients with duration of disease of 5 to $<10$ years. In patients with CAD of 10 years or longer, AEs were reported in $4.26 \%$. AEs were reported in $4.64,4.83$, and $8.03 \%$ of CCS class I, class II, and class III and IV patients, respectively. AEs were reported in $6.91 \%$ of patients with a previous PCI and in $3.86 \%$ of patients without a PCI.

Fig. 1 Antianginal effectiveness after 4 months of treatment in a overall population, $\mathbf{b}$ age subgroups, $\mathbf{c}$ CAD duration subgroups, d CCS Class subgroups, and e medical history subgroups. Bars represent relative changes from baseline (percentages). Values shown inside bars are absolute changes from baseline (mean $\pm \mathrm{SD}$ ). ${ }^{*} p<0.001$ for all changes between baseline and month 4. CAD coronary artery disease, CCS Canadian Cardiovascular Society, $C O P D$ chronic obstructive pulmonary disease, $H T$ hypertension, $M I$ myocardial infarction, $P C I$ percutaneous coronary intervention 


\section{(A) Overall population}

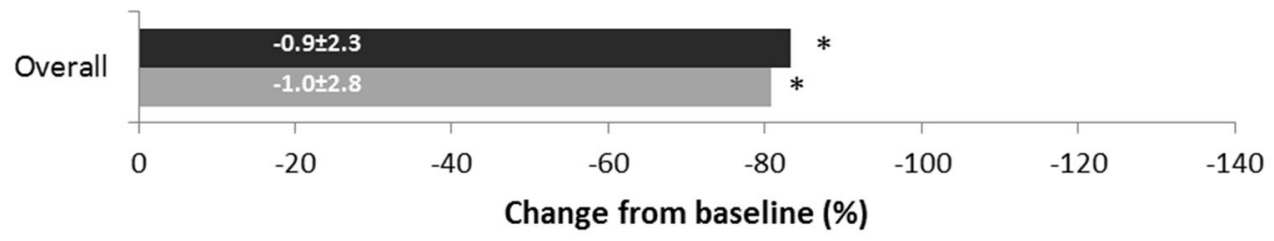

(B) Age

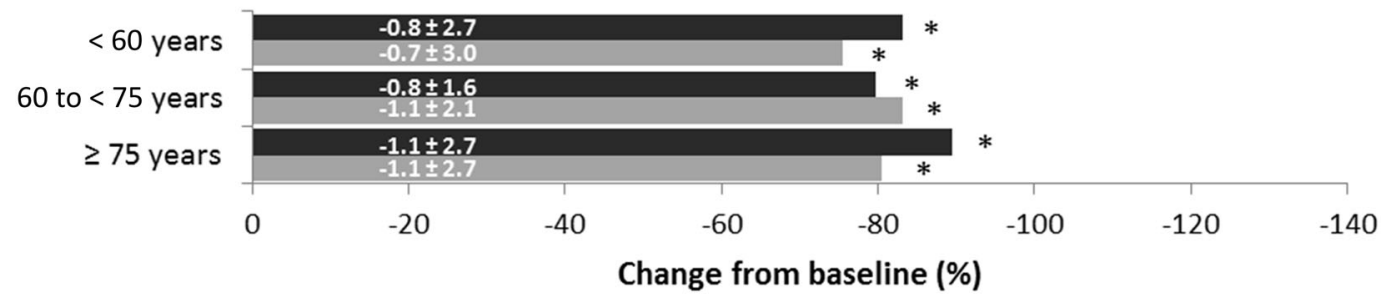

(C) CAD duration

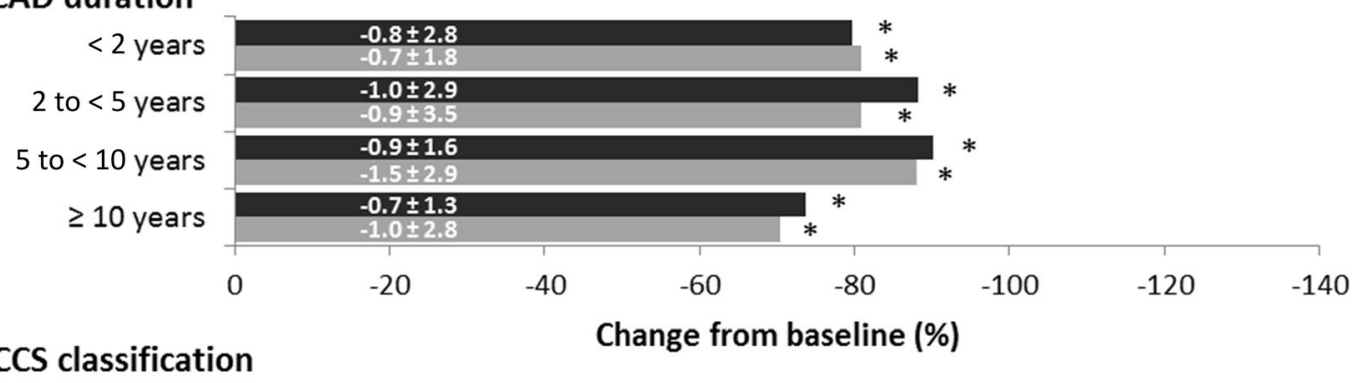

(D) CCS classification

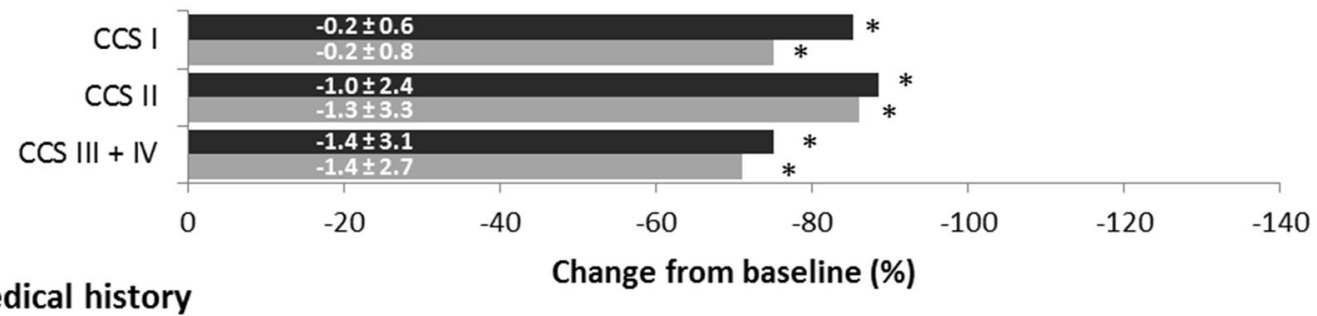

(E) Medical history

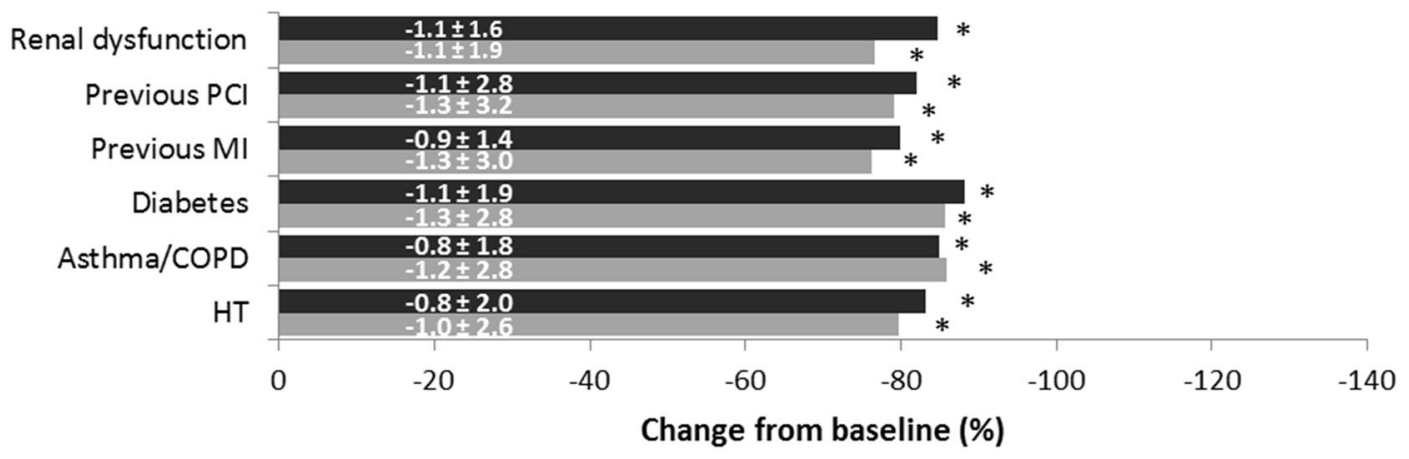

- Angina attacks/week Short-acting nitrates taken/week 
Table 1 Heart rate in the different subpopulations at baseline and at 4 months

\begin{tabular}{llll}
\hline & $n(\%)$ & HR at baseline $(\mathbf{b p m})$ & HR at M4 (bpm) \\
\hline Overall population & $747(100.0 \%)$ & $76.8 \pm 11.8$ & $67.2 \pm 8.2^{*}$ \\
Age $<60$ years & $192(25.7 \%)$ & $77.3 \pm 12.0$ & $67.6 \pm 8.0^{*}$ \\
Age 60 to $<75$ years & $357(47.8 \%)$ & $76.4 \pm 11.3$ & $66.7 \pm 8.1^{*}$ \\
Age $\geq 75$ years & $182(24.4 \%)$ & $77.3 \pm 12.4$ & $67.9 \pm 8.6^{*}$ \\
CAD duration $<2$ years & $226(30.2 \%)$ & $76.6 \pm 11.9$ & $67.5 \pm 8.6^{*}$ \\
CAD duration 2 to <5 years & $182(24.4 \%)$ & $77.5 \pm 11.4$ & $67.5 \pm 8.4^{*}$ \\
CAD duration 5 to <10 years & $185(24.8 \%)$ & $77.4 \pm 12.0$ & $66.6 \pm 7.3^{*}$ \\
CAD duration $\geq 10$ years & $139(18.6 \%)$ & $75.5 \pm 11.7$ & $67.2 \pm 8.6^{*}$ \\
CCS class I & $187(25.0 \%)$ & $76.9 \pm 12.0$ & $67.6 \pm 8.3^{*}$ \\
CCS class II & $389(52.1 \%)$ & $76.7 \pm 11.7$ & $67.0 \pm 8.2^{*}$ \\
CCS III + IV & $134(17.9 \%)$ & $77.4 \pm 11.1$ & $67.5 \pm 8.0^{*}$ \\
Hypertension & $635(85.0 \%)$ & $76.8 \pm 11.8$ & $67.3 \pm 8.3^{*}$ \\
Asthma/COPD & $141(18.9 \%)$ & $78.6 \pm 12.4$ & $67.0 \pm 8.5^{*}$ \\
Diabetes & $255(34.1 \%)$ & $77.0 \pm 11.8$ & $67.2 \pm 8.2^{*}$ \\
Previous MI & $230(30.8 \%)$ & $74.7 \pm 12.2$ & $65.8 \pm 8.9^{*}$ \\
Previous PCI & $369(49.4 \%)$ & $75.3 \pm 11.8$ & $65.8 \pm 7.8^{*}$ \\
Renal dysfunction & $65(8.7 \%)$ & $77.1 \pm 12.3$ & $67.3 \pm 8.6^{*}$ \\
\hline
\end{tabular}

${ }^{*} p<0.0001$ for all changes between baseline and month 4

bpm beats per minute, CAD coronary artery disease, CCS Canadian Cardiovascular Society, COPD chronic obstructive pulmonary disease, $H R$ heart rate, $M 4$ month 4, $M I$ myocardial infarction, $P C I$ percutaneous coronary intervention

\section{DISCUSSION}

This is the first study to assess the effectiveness of the metoprolol/ivabradine FDC in patient subgroups relevant to real-life clinical practice. We observed an additional reduction in HR, weekly angina attacks and SAN consumption at 4 months as well as a relevant improvement in the functional status of patients, with the proportion of patients in CCS class I (meaning asymptomatic at normal activity levels) increasing significantly versus baseline. Moreover, an improvement in self-reported medication adherence was reported with the use of the FDC. These beneficial effects were consistently found in all analyzed subgroups, regardless of age, CAD duration, comorbidities, previous MI, or history of revascularization.

The beneficial effects of combining ivabradine with a BB have been shown in several previously published studies with a similar

Fig. 2 Changes in CCS class after 4 months of treatment in $\mathbf{a}$ overall population, $\mathbf{b}$ age subgroups, $\mathbf{c}$ CAD duration subgroups and $\mathbf{d}$ medical history subgroups. Bars represent the proportion of patients with CCS class I, at baseline and at month $4 .{ }^{*} p<0.001$ for all changes between baseline and month 4. CAD coronary artery disease, $C C S$ Canadian Cardiovascular Society, COPD chronic obstructive pulmonary disease, $H T$ hypertension, $M I$ myocardial infarction, M4 month 4, $P C I$ percutaneous coronary intervention 
(A) Overall population

(B) Age
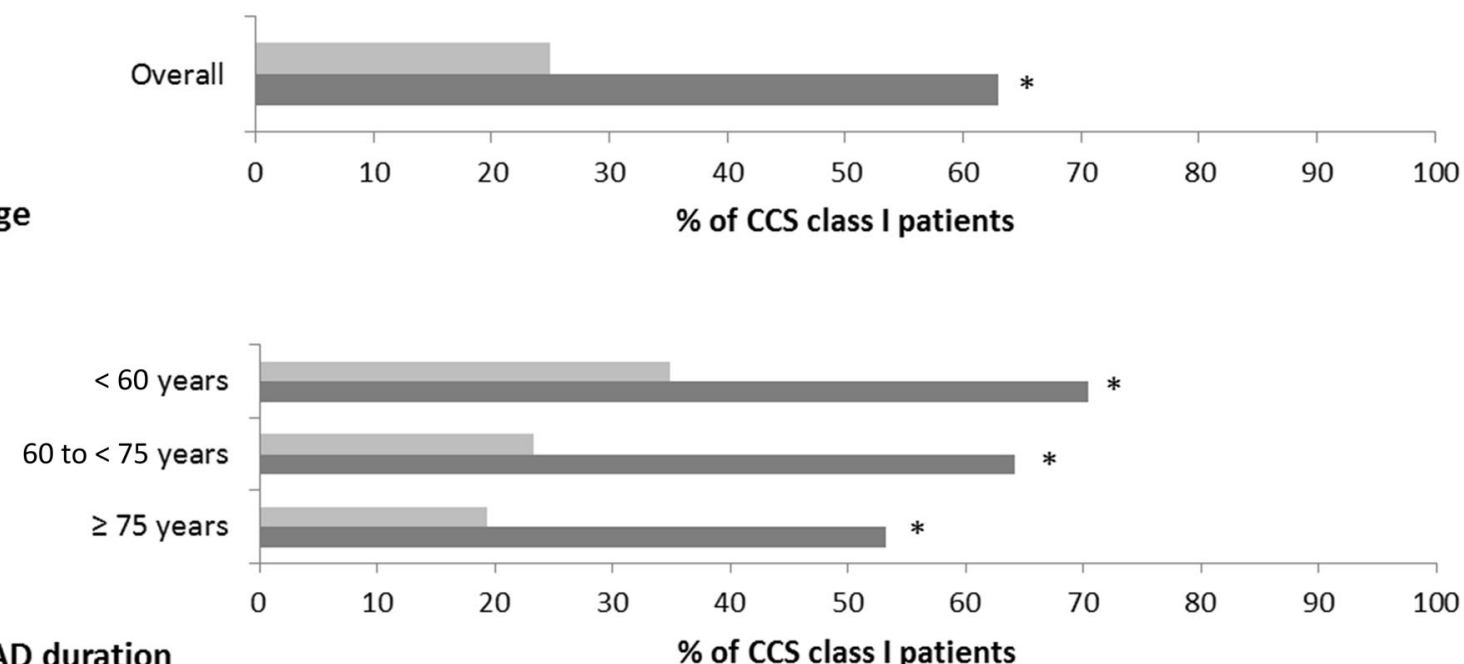

(C) CAD duration

$\%$ of CCS class I patients

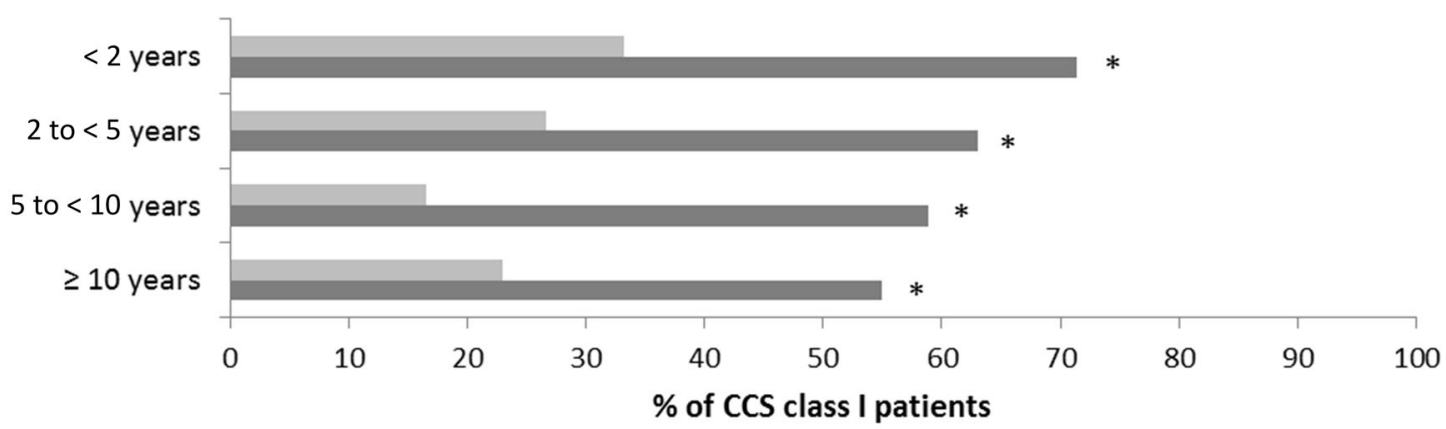

(D) Medical history

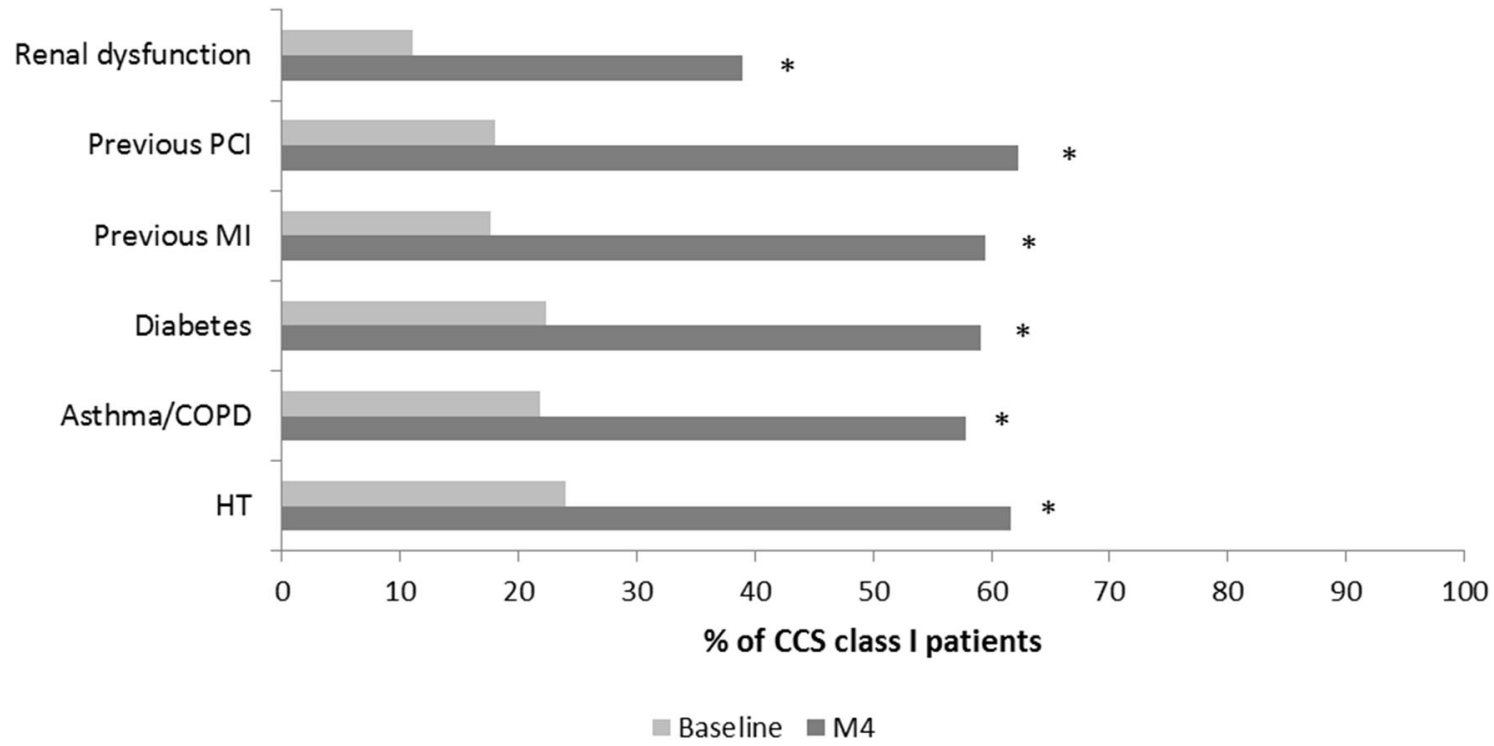




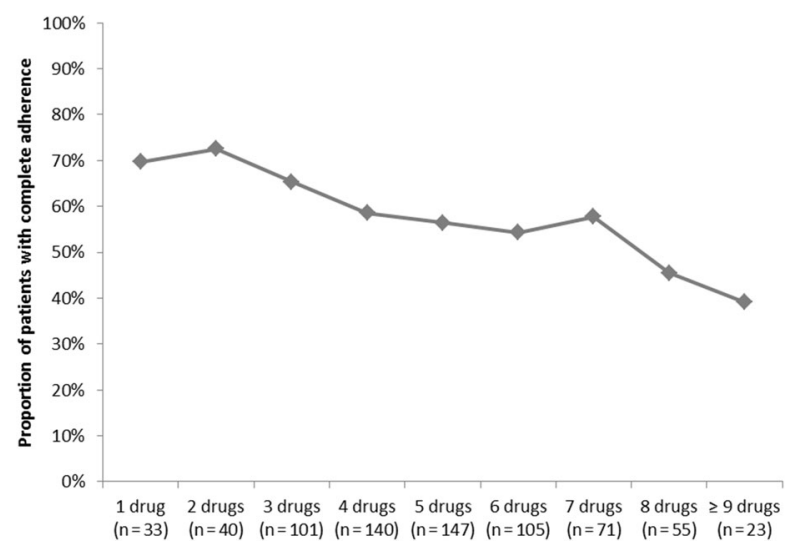

Fig. 3 Complete adherence in relation to number of drugs taken at final visit $(n=715$ patients). $p=0.0004$

design. The ASSOCIATE study [11] showed that combining ivabradine with atenolol $50 \mathrm{mg}$ led to an improvement in exercise tolerance test parameters. In the ADDITIONS study, in which more than 2000 patients were prospectively followed for 4 months, combining ivabradine with a BB in stable angina patients led to an additional reduction in $\mathrm{HR}$, weekly angina attacks, and nitrate consumption [12]. An observational, prospective, open-label study in 2403 Greek patients with chronic stable angina receiving ivabradine in combination with $\mathrm{BBs}$ showed antianginal effectiveness and improvement in quality of life (QoL) [21].

The benefits of the ivabradine and BB combination have also been demonstrated in specific patient subpopulations, including the elderly, post-PCI patients, and patients with comorbidities. In elderly patients ( $\geq 80$ years old) with stable angina, the 4-month, open-label, observational REDUCTION study [22] reported a significant improvement in $\mathrm{HR}$, angina attack frequency, and SAN consumption with ivabradine twice daily combined with a BB. A subgroup analysis of the ADDITIONS study in elderly patients ( $\geq 75$ years old) also found that the addition of ivabradine to a BB effectively reduced HR, angina attacks, and nitrate consumption, and improved CCS symptom scores and QoL [23]. The antianginal effectiveness of ivabradine administration in addition to a BB has also been shown in post hoc analyses of two observational studies in stable angina patients post-revascularization $[24,25]$. A pooled analysis of eight multicenter, randomized, double-blind studies in patients with stable angina found similar reductions in HR and angina attack frequency both in patients with and without diabetes mellitus [26]. A recent analysis of pooled data from three observational studies in 8555 stable angina patients receiving ivabradine $2.5 \mathrm{mg}, 5 \mathrm{mg}$, or $7.5 \mathrm{mg}$ twice daily for 4 months found a significant reduction in angina attack frequency and SAN consumption of $87 \%$ [27]. Ivabradine was effective and safe in all subpopulations of angina patients seen in clinical practice, independent of age, comorbidities, and use of BBs.

In our study, the average dose of metoprolol was $78.4 \mathrm{mg}$ and $86.1 \mathrm{mg}$ at study entry and at 4 months, respectively, which is important in terms of the co-morbidity profile of most angina patients who cannot tolerate high doses of BB.

In a recent publication based on a Danish registry with more than 156,000 CAD patients, it was estimated that within a 10 -year period, the average age had significantly increased by 2.1 years, reaching 63.9 years, with the burden of comorbidities also being significantly elevated [28]. Consistent with these findings, in patients with stable angina included in the CLARIFY registry, the average age was 64 years and co-morbid conditions were frequent (hypertension was present in $71 \%$ of patients, lipid abnormalities in $75 \%$, chronic renal disease in $22 \%$, diabetes in $29 \%$, heart failure in $15 \%$, peripheral artery disease in $10 \%$, and asthma/ COPD in 7\%) [29]. This suggests that difficultto-treat subpopulations of patients who are older and have more co-morbidities will be increasingly relevant to clinical practice. Our

Fig. 4 Changes in adherence after 4 months of treatment in $\mathbf{a}$ overall population, $\mathbf{b}$ age subgroups, $\mathbf{c}$ CAD duration subgroups, d CCS Class subgroups, and (e) medical history subgroups. Bars represent the proportion of patients with complete adherence. ${ }^{*} p<0.001$ for all changes between baseline and month 4. CAD coronary artery disease, $C C S$ Canadian Cardiovascular Society, COPD chronic obstructive pulmonary disease, $H T$ hypertension, $M I$ myocardial infarction, M4 month 4, PCI percutaneous coronary intervention 


\section{(A) Overall population}

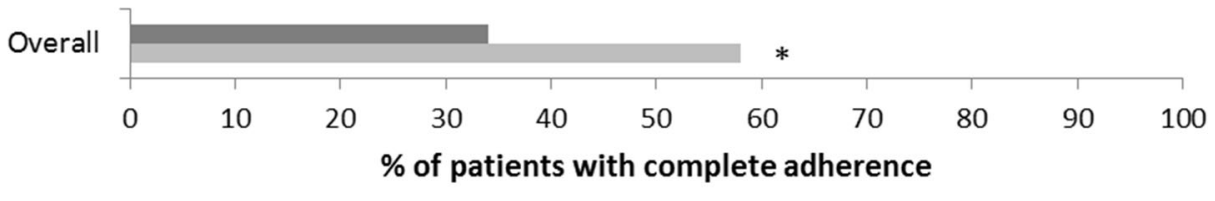

(B) Age

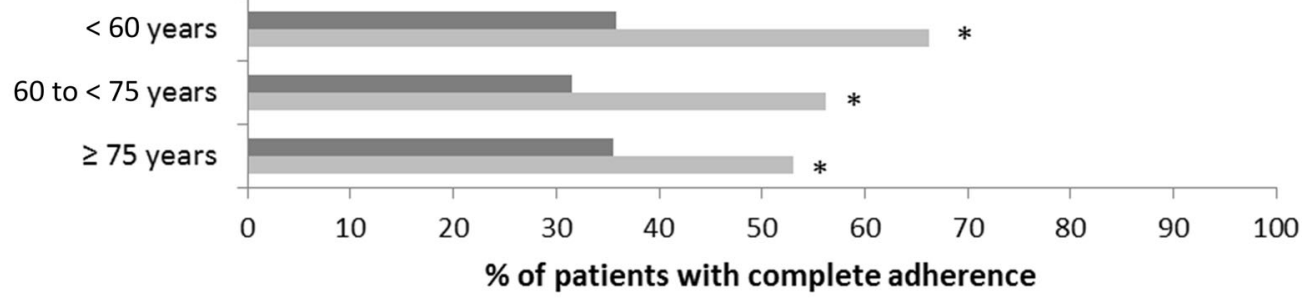

(C) CCS classification

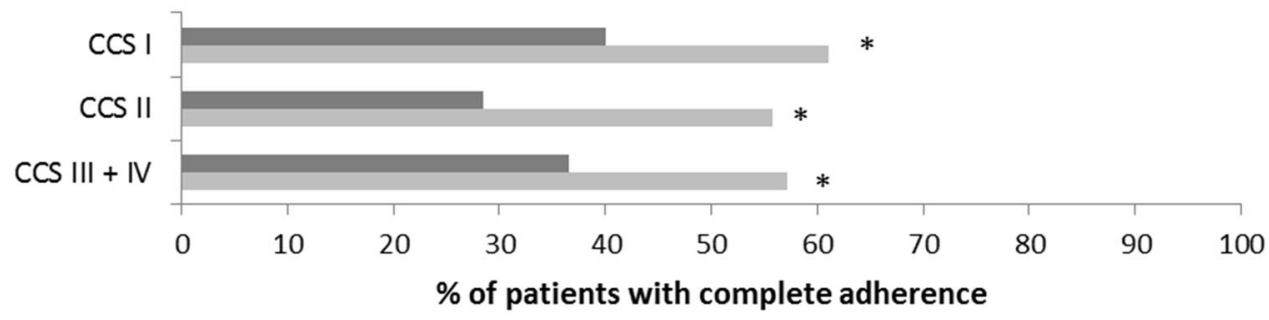

(D) CAD duration

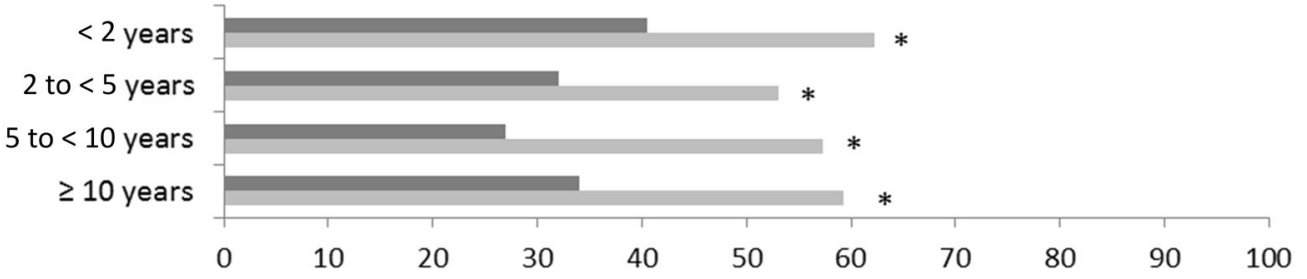

(E) Medical history

$\%$ of patients with complete adherence

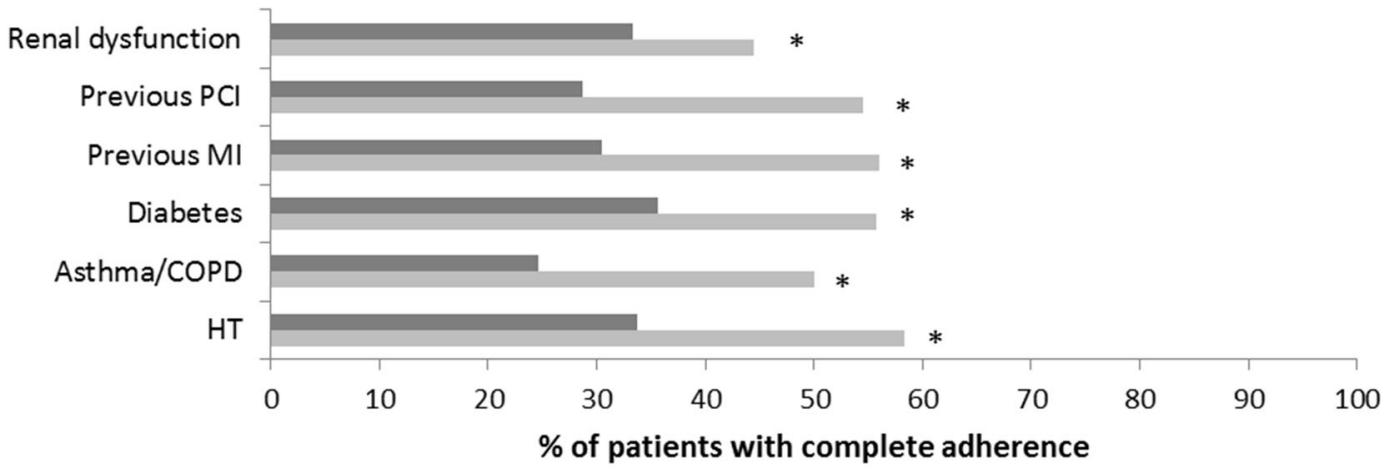

naseline $\square$ M4 
Table 2 Tolerability assessment by physicians in the different subpopulations at 4 months

\begin{tabular}{|c|c|c|c|}
\hline \multirow[t]{2}{*}{ Patient subgroups } & \multicolumn{3}{|c|}{ Tolerability } \\
\hline & $\begin{array}{l}\text { Very } \\
\text { good } \\
(\%)\end{array}$ & $\begin{array}{l}\text { Good } \\
(\%)\end{array}$ & $\begin{array}{l}\text { Moderate or } \\
\text { poor }(\%)\end{array}$ \\
\hline Age $<60$ years & 78.1 & 21.4 & 0.5 \\
\hline Age 60 to $<75$ years & 76.6 & 21.7 & 1.7 \\
\hline Age $\geq 75$ years & 69.7 & 29.2 & 1.1 \\
\hline $\begin{array}{l}\text { CAD } \\
\text { duration }<2 \text { years }\end{array}$ & 75.4 & 23.7 & 0.9 \\
\hline $\begin{array}{l}\text { CAD duration } 2 \\
\text { to }<5 \text { years }\end{array}$ & 71.2 & 27.7 & 1.1 \\
\hline $\begin{array}{l}\text { CAD duration } 5 \\
\text { to }<10 \text { years }\end{array}$ & 79.0 & 20.4 & 0.6 \\
\hline $\begin{array}{l}\text { CAD } \\
\text { duration } \geq 10 \text { years }\end{array}$ & 74.8 & 22.1 & 3.1 \\
\hline CCS class I & 73.4 & 26.1 & 0.5 \\
\hline CCS class II & 75.9 & 23.1 & 1.0 \\
\hline CCS III + IV & 77.1 & 20.6 & 2.3 \\
\hline Hypertension & 75.5 & 23.1 & 1.5 \\
\hline Asthma/COPD & 74.6 & 23.9 & 1.4 \\
\hline Diabetes & 79.1 & 19.7 & 1.2 \\
\hline Previous MI & 77.0 & 22.1 & 0.9 \\
\hline Previous PCI & 76.4 & 22.2 & 1.2 \\
\hline Renal dysfunction & 71.4 & 27.0 & 1.6 \\
\hline
\end{tabular}

Values are expressed as proportions of patients

study suggests that the benefits of metoprolol/ ivabradine treatment are also observed in these subpopulations.

In our analysis, we also found an improvement in self-reported medication adherence across all patient subgroups with the use of a FDC. At baseline, complete adherence was low, ranging from $25 \%$ to $40 \%$ of patients depending on the subgroup, while after 4 months of treatment with metoprolol/ivabradine complete adherence was observed in $44 \%$ to $66 \%$, nearly doubling in some of the subgroups. One possible explanation for this increase in adherence could be the improvement in clinical status. Nevertheless, given the fact that the treatment was added to already-existing antianginal treatment and the initially low number of angina attacks and SAN consumption, we might speculate that the beneficial effect of metoprolol/ivabradine FDC was related to treatment simplification by combining two individual components of previously used antianginal therapy in a single-pill combination. Indeed, FDCs have been reported to improve adherence as compared to free combinations $[30,31]$. As adherence declines with an increasing number of drugs, treatment simplification might be particularly relevant for patients taking several medications, as is often the case for elderly patients or those with comorbidities, which were included in the subpopulations analyzed in the present study.

\section{Study Limitations}

The study has limitations inherent in the nature of its design (open-label, observational), which may have resulted in bias towards overestimating the treatment effect. Other limitations are the absence of a placebo group and assessment of adherence by the indirect method of patient self-reporting and at a relatively short follow-up period, which might have led to overestimation of the effect on adherence.

\section{CONCLUSIONS}

This prospective, multicenter, observational 4-month study found that treatment with the metoprolol/ivabradine FDC significantly reduced HR, decreased the frequency of angina attacks and SAN use, and improved patient functional status and medication adherence in patient subgroups relevant to real-life clinical practice.

\section{ACKNOWLEDGEMENTS}

The authors would like to thank the participants of the study. 
Funding. Sponsorship for this study was provided by Servier Deutschland GmbH. Editorial assistance and the Rapid Service Fee were funded by Servier, France. All authors had full access to all of the data in this study and take complete responsibility for the integrity of the data and accuracy of the data analysis.

\section{Medical Writing and Editorial Assis-} tance. Writing and editorial assistance was provided by Dr. Diana Toli (Servier, France).

Authorship. All named authors meet the International Committee of Medical Journal Editors (ICMJE) criteria for authorship for this article, take responsibility for the integrity of the work as a whole, and have given their approval for this version to be published.

Prior Presentations. There are no prior presentations of this work.

Disclosures. Dr. Dimitar Divchev received honoraria for lectures and as scientific coordinator of this study from Servier. Dr. Georg Stöckl is an employee of Servier Deutschland $\mathrm{GmbH}$, Munich (Medical Affairs Department).

Compliance with Ethics Guidelines. All procedures followed were in accordance with the ethical standards of the responsible committee on human experimentation (institutional and national) and with the Helsinki Declaration of 1964, as revised in 2013. Informed consent was obtained from all patients for being included in the study. Ethical approval was granted by the independent ethics commission in Freiburg/Germany (FEKI).

Data Availability. The datasets during and/ or analyzed during the current study are available from the corresponding author on reasonable request.

Open Access. This article is distributed under the terms of the Creative Commons Attribution-NonCommercial 4.0 International License (http://creativecommons.org/licenses/ by-nc/4.0/), which permits any noncommercial use, distribution, and reproduction in any medium, provided you give appropriate credit to the original author(s) and the source, provide a link to the Creative Commons license, and indicate if changes were made.

\section{REFERENCES}

1. Roth GA, Johnson C, Abajobir A, et al. Global, regional, and national burden of cardiovascular diseases for 10 causes, 1990 to 2015. J Am Coll Cardiol. 2017;70:1-25.

2. Vos T, Flaxman AD, Naghavi M, et al. Years lived with disability (YLDs) for 1160 sequelae of 289 diseases and injuries 1990-2010: a systematic analysis for the Global Burden of Disease Study 2010. Lancet. 2012;380:2163-96.

3. Heusch G. Pleiotropic action(s) of the bradycardic agent ivabradine:cardiovascular protection beyond heart rate reduction. $\mathrm{Br} \mathrm{J}$ Pharmacol. 2008;155:970-1.

4. Panza JA, Diodati JG, Callahan TS, Epstein SE, Quyyumi AA. Role of increases in heart rate in determining the occurrence and frequency of myocardial ischemia during daily life in patients with coronary artery disease. J Am Coll Cardiol. 1992;20:1092-8.

5. Andrews TC, Fenton T, Toyosaki N, et al. Subsets of ambulatory myocardial ischemia based on heart rate activity. Circadian distribution and response to anti-ischemic medication. The Angina and Silent Ischemia Study Group (ASIS). Circulation. 1993;88:92-100.

6. Pratt CM, McMahon RP, Goldstein S, et al. Comparison of subgroups assigned to medical regimens used to suppress cardiac ischemia (the Asymptomatic Cardiac Ischemia Pilot [ACIP] study). Am J Cardiol. 1996;77:1302-9.

7. Palatini P. Heart rate: a strong predictor of mortality in subjects with coronary artery disease. Eur Heart J. 2005;26:943-5.

8. Diaz A, Bourassa MG, Guertin MC, Tardif JC. Longterm prognostic value of resting heart rate in patients with suspected or proven coronary artery disease. Eur Heart J. 2005;26:967-74.

9. Members Task Force, Montalescot G, Sechtem U, Achenbach S, et al. ESC guidelines on the management of stable coronary artery disease: the Task Force on the management of stable coronary artery disease of the European Society of Cardiology. Eur Heart J. 2013;2013(34):2949-3003. 
10. Tendera M, Fox K, Ferrari R, et al. CLARIFY Registry Investigators. Inadequate heart rate control despite widespread use of beta-blockers in outpatients with stable CAD: findings from the international prospective CLARIFY registry. Int $\mathrm{J}$ Cardiol. 2014;176:119-24.

11. Tardif JC, Ponikowski P, Kahan T; ASSOCIATE Study Investigators. Efficacy of the I(f) current inhibitor ivabradine in patients with chronic stable angina receiving beta blocker therapy: a 4-month, randomized, placebo-controlled trial. Eur Heart J. 2009;30:540-548.

12. Werdan K, Ebelt H, Nuding S, Hopfner F, Hack G, Muller-Werdan U. Ivabradine in combination with beta-blocker improves symptoms and quality of life in patients with stable angina pectoris: results from the ADDITIONS study. Clin Res Cardiol. 2012;101:365-73.

13. DiFrancesco D. Cardiac pacemaker I(f) current and its inhibition by heart rate-reducing agents. Curr Med Res Opin. 2005;21:1115-22.

14. DiFrancesco D, Camm AJ. Heart rate lowering by specific and selective I(f) current inhibition with ivabradine. A new therapeutic perspective in cardiovascular disease. Drugs. 2004;64:1757-1765.

15. Kronish I, Ye S. Adherence to cardiovascular medication: lessons learned and future direction. Prog Cardiovasc Dis. 2013;55:590-600.

16. Kardas P; COMPASS Investigators. Comparison of once daily versus twice daily oral nitrates in stable angina pectoris. Am J Cardiol. 2004;94:213-6.

17. Newby LK, LaPointe NM, Chen AY, et al. Long-term adherence to evidence-based secondary prevention therapies in coronary artery disease. Circulation. 2006;113:203-12.

18. Ferdinand KC, Senatore FF, Clayton-Jeter H, et al. Improving medication adherence in cardiometabolic disease: practical and regulatory implications. J Am Coll Cardiol. 2017;69:437-51.

19. Claxton AJ, Cramer J, Pierce C. A systematic review of the associations between dose regimens and medication compliance. Clin Ther. 2001;23:1296-310.

20. Divchev D, Stöckl G; Study Investigators. Treatment of stable angina with a new fixed-dose combination of ivabradine and metoprolol: effectiveness and tolerability in routine clinical practice. Cardiol Ther. 2017;6:239-249.

21. Zarifis J, Grammatikou V, Kallistratos M, Katsivas A; Investigators of the Prospective, Noninterventional, Observational Study of the Antianginal Efficacy of Ivabradine During a 4-Month Treatment of a Greek
Population With Coronary Artery Disease. Treatment of stable angina pectoris with ivabradine in everyday practice: a pan-Hellenic, prospective, noninterventional study. Clin Cardiol. 2015;38(12):725-32.

22. Koester R, Kaehler J, Meinertz T. Ivabradine for the treatment of stable angina pectoris in octogenarians. Clin Res Cardiol. 2011;100(2):121-8.

23. Müller-Werdan U, Stöckl G, Ebelt H, Nuding S, Höpfner F, Werdan K; ADDITIONS Study Investigators. Ivabradine in combination with betablocker reduces symptoms and improves quality of life in elderly patients with stable angina pectoris: age-related results from the ADDITIONS study. Exp Gerontol. 2014;59:34-41.

24. Werdan K, Ebelt H, Nuding S, Höpfner F, Stöckl G, Müller-Werdan U. Ivabradine in combination with beta-blockers in patients with chronic stable angina after percutaneous coronary intervention. Adv Ther. 2015;32:120-37.

25. Zarifis J, Grammatikou V, Kallistratos M, Katsivas A. Antianginal efficacy of ivabradine in patients with history of coronary revascularization. Angiology. 2017;68:10-8.

26. Borer JS, Tardif JC. Efficacy of ivabradine, a selective I(f) inhibitor, in patients with chronic stable angina pectoris and diabetes mellitus. Am J Cardiol. 2010;105:29-35.

27. Werdan K, Perings S, Köster R, et al. Effectiveness of ivabradine treatment in different subpopulations with stable angina in clinical practice: a pooled analysis of observational studies. Cardiology. 2016;135:141-50.

28. Jørgensen ME, Andersson C, Olsen AM, et al. Danish trends in pharmacotherapy, comorbidities, and demographics in patients referred for coronary angiography: what changed during a decade? Eur Heart J Cardiovasc Pharmacother. 2015;1:157-65.

29. Sorbets E, Greenlaw N, Ferrari R, et al; CLARIFY Investigators. Rationale, design, and baseline characteristics of the CLARIFY registry of outpatients with stable coronary artery disease. Clin Cardiol. 2017;40:797-806.

30. Bangalore S, Kamalakkannan G, Parkar S, Messerli FH. Fixed-dose combinations improve medication compliance: a meta-analysis. Am J Med. 2007;120:713-9.

31. Balu S, Simko RJ, Quimbo RM, Cziraky MJ. Impact of fixed-dose and multi-pill combination dyslipidemia therapies on medication adherence and the economic burden of sub-optimal adherence. Curr Med Res Opin. 2009;25:2765-75. 